\title{
Uma proposta de cadeia de valor da educação pública básica brasileira
}

\author{
A proposal for a brazilian basic public education value chain \\ Una propuesta para una cadena de valor de la educación pública básica brasileña
}

Recebido: 08/08/2021 | Revisado: 11/09/2021 | Aceito: 07/09/2021 | Publicado: 09/09/2021

\author{
Bruno Francisco Batista Dias \\ ORCID: https://orcid.org/0000-0001-9037-9592 \\ Universidade do Grande Rio, Brasil \\ E-mail: brunofbd@id.uff.br \\ Deborah Moraes Zouain \\ ORCID: https://orcid.org/0000-0003-4813-9741 \\ Universidade do Grande Rio, Brasil \\ E-mail: deborahzouain@gmail.com
}

\begin{abstract}
Resumo
Este artigo apresenta uma proposta de cadeia de valor para a educação pública básica brasileira. Para tanto, nos valemos da proposta de análise da geração de valor de Michael Porter, de modo a identificar as atividades primárias e secundárias dessa cadeia. O procedimento metodológico adotado foi a revisão bibliográfica, em que se fez uma minuciosa leitura das publicações relevantes relativas ao tema a fim de captar as nuances dos processos realizados no âmbito da prestação de serviços educacionais públicos capazes de gerar valor. $\mathrm{O}$ resultado da investigação nos permitiu propor uma cadeia formada por duas atividades secundárias (A.S) e duas atividades primárias (A.P): (A.S.1) Regulamentação e Planejamento; (A.S.2) Avaliação e Acompanhamento; (A.P.1) Gestão Escolar; (A.P. 2) Práticas Pedagógicas.
\end{abstract}

Palavras-chave: Cadeia de valor; Educação pública; Educação básica.

\begin{abstract}
This study engaged in a value chain model for Brazilian basic public education. For that, we used Porter's value creation analysis proposal, in order to identify the primary and secondary activities of this chain. The methodological procedure adopted was a literature review, in which publications related to the topic were read in detail, in order to capture the nuances of the processes carried out in the context of providing public educational services capable of generating value. The result of the investigation into risks proposes a chain formed by two secondary activities (A.S) and two primary activities (A.P): (A.S.1) Regulation and Planning; (A.S.2) Evaluation and Monitoring; (A.P.1) School Management; (A.P. 2) Pedagogical Practices.
\end{abstract}

Keywords: Value chain; Public education; Basic education.

\section{Resumen}

Este estudio se involucró en un modelo de cadena de valor para la educación pública básica brasileña. Para eso, utilizamos la propuesta de análisis de creación de valor de Porter, con el fin de identificar las actividades primarias y secundarias de esta cadena. El procedimiento metodológico adoptado fue una revisión de la literatura, en la que se leyeron en detalle publicaciones relacionadas con el tema, con el fin de captar los matices de los procesos llevados a cabo en el contexto de la prestación de servicios educativos públicos capaces de generar valor. El resultado de la investigación de riesgos propone una cadena formada por dos actividades secundarias (A.S) y dos actividades primarias (A.P): (A.S.1) Regulación y Planificación; (A.S.2) Evaluación y seguimiento; (A.P.1) Gestión escolar; (A.P.2) Prácticas pedagógicas.

Palabras clave: Cadena de valor; Educacion publica; Educacion basica.

\section{Introdução}

A educação como um serviço essencial ao desenvolvimento humano, econômico e social, se assemelha a um bem "Bem Público" por sua capacidade de gerar externalidades positivas que afetam toda a sociedade. Por isso, acaba por ser de dever do Estado ofertá-la, pois pode ser instrumento de transformação social, permitindo a todos os indivíduos acesso aos conhecimentos, habilidades e atitudes necessárias a vida adulta plena e emancipada (Sobrinho, 2013; Araújo \& Cassini, 2017; de Mira \& De Carvalho, 2020). 
No Brasil, somente com a Constituição de 1988 (CF88) reconheceu-se a necessidade de ofertar de forma gratuita e universal a educação básica, isto é, os módulos de ensino formalmente conhecidos como educação infantil, ensino fundamental e ensino médio. De fato, a universalização desse serviço só veio a ocorrer 20 anos depois da promulgação da carta de direitos de 88. Porém, a oferta plena desse serviço, ainda, não vem sendo acompanhada da melhoria da qualidade do ensino (Moraes, Menezes \& Dias, 2019). Em outras palavras, o Estado brasileiro, ainda, não é capaz de ofertar uma educação que atenda os princípios que a categorize como bem público: oferta gratuita, ecumênica e, acima de tudo, de qualidade.

São estes alguns dos principais problemas de qualidade do serviço educacional ofertado pelo Estado brasileiro: altas taxas de analfabetismo funcional, dado a expressiva quantidade de estudantes que concluem a primeira etapa do ensino fundamental sem competências elementares de leitura e de matemática; estagnação do fluxo escolar, apontada pelos elevados valores dos índices de distorção idade-série; baixa qualidade do ensino oferecido nas escolas públicas brasileiras, considerando a ingerência na formação de indivíduos com as competências necessárias à vida adulta (Haddad \& Siqueira, 2015; Moraes, Menezes \& Dias, 2019).

Nesse sentido, a proposta deste estudo consiste em analisar a oferta de serviços educacionais, especificamente os da educação pública básica brasileira, para responder o seguinte questionamento: Qual é a estrutura básica (conjunto de atividades) da cadeia de valor da educação básica brasileira? Encontrar respostas a essa pergunta pode vir a fornecer um melhor entendimento do que realmente agrega valor aos serviços educacionais, e, consequentemente, auxiliar no desenvolvimento de soluções aos problemas apontados, no que tange a baixa qualidade dos serviços educacionais ofertados pelo Estado brasileiro.

Destaca-se, ainda, que o conceito de valor adotado neste estudo, de forma genérica, pode ser entendido como o resultado dos benefícios percebidos pelas partes interessadas (Porter, 1985; 1999). Por sua vez, a cadeia de valor seria, então, como um conjunto organizado e pré-estabelecido de atividades, realizada pela organização, cuja execução é a responsável por propiciar a essas partes interessadas “valor” (Porter, 1985).

Para alcançar os fins propostos, este artigo foi estruturado em seis seções, sendo a primeira esta introdução. Na sequência, apresenta-se uma breve revisão do conceito de cadeia de valor e as premissas que serão utilizadas ao longo do trabalho. Na seção três, têm-se os procedimentos metodológicos utilizados na pesquisa, enquanto na quarta seção apresenta-se uma proposta de cadeia de valor para a educação pública básica. Por fim, são realizadas as considerações finais e são propostas possíveis futuras questões de pesquisa.

\section{Cadeia de valor}

Segundo Porter (1985), o conceito de geração de valor consiste em prover por meio de produtos ou serviços um estado de bem-estar aos consumidores e todas as demais partes interessadas da organização. O valor, também, pode ser definido de duas formas: como a percepção dos benefícios que os sujeitos obtêm ao consumir um determinado bem ofertado (valor direto); ou a percepção dos benefícios ao serem afetados pelo consumo do produto por terceiros ou pela sua fabricação (valor indireto) (Porter, 1985; 1989). Em relação aos serviços públicos, segundo Heintzman e Marson (2005), além dos componentes já citados, a geração de valor, ainda, estaria condicionada à adequada relação de confiança e satisfação entre os integrantes dessa cadeia.

Essa percepção de bem-estar pode vir a ser influenciada por um conjunto diverso de características subjetivas e objetivas do produto ou serviço ofertado (Parasuraman, Zeithaml \& Berry, 1985). Quanto aos aspectos relativos à objetividade que afetam a percepção de valor, estes são determinados por critérios como o custo-benefício, a durabilidade, a qualidade dos materiais empregados, entre outros. Por sua vez, em termos de subjetividade da avaliação, considera-se como critério de valor 
a percepção daquilo que se esperava e o que de fato foi recebido com o consumo do serviço ou produto (Zeithaml, Bitner \& Gremler; 2014).

Porter (1985;1999), delineia como deve ser uma análise apurada de um processo específico de geração de valor por parte de organização. Nesse sentido, aponta-se que para a análise ser bem-sucedida, faz-se necessário que se seja feita uma investigação detalhada de todo o processo, da concepção à entrega final do produto ou serviço, considerando aquilo que, de essencial, a organizacional faz para alcançar a percepção de valor por parte do cliente (Zeithaml, Bitner \& Gremler, 2014). Porém, essa análise não se limita a identificar os níveis de eficiência ou eficácia dos processos produtivos. Pois, enquanto a investigação da eficiência e eficácia objetivam identificar aspectos relativos a economicidade e o alinhamento dos meios aos fins, a análise da geração de valor vai além, isto é, se propõe mapear o que, de fato, faz sentido a organização realizar, tendo como critério de seleção os aspectos imanentes ao processo produtivo e elementos relacionados com a geração de valor (Nagariya, Kumar \& Kumar, 2020).

Por isso, a melhor forma de se identificar os processos de geração de valor por uma organização é por meio da construção de uma cadeia de valor (Jelassi \& Martínez-López, 2020). Por cadeia de valor se entende o conjunto de componentes interrelacionados, isto é, atividades, tarefas e processos da produção de um produto ou serviço que são capazes de gerar valor (Porter, 1985). Em outros termos, a cadeia de valor trata de um modelo representativo dos processos de geração de valor, obtidos por meio da abstração de uma realidade concreta. Esse modelo costuma ser apresentado de diversas formas, sendo o mais usual a proposta de Michael Porter, conforme Figura 1, em que se representa os componentes internos responsáveis pela geração de valor para o setor industrial.

Figura 1. Modelo genérico de uma Cadeia de Valor proposto por Porter (1985).

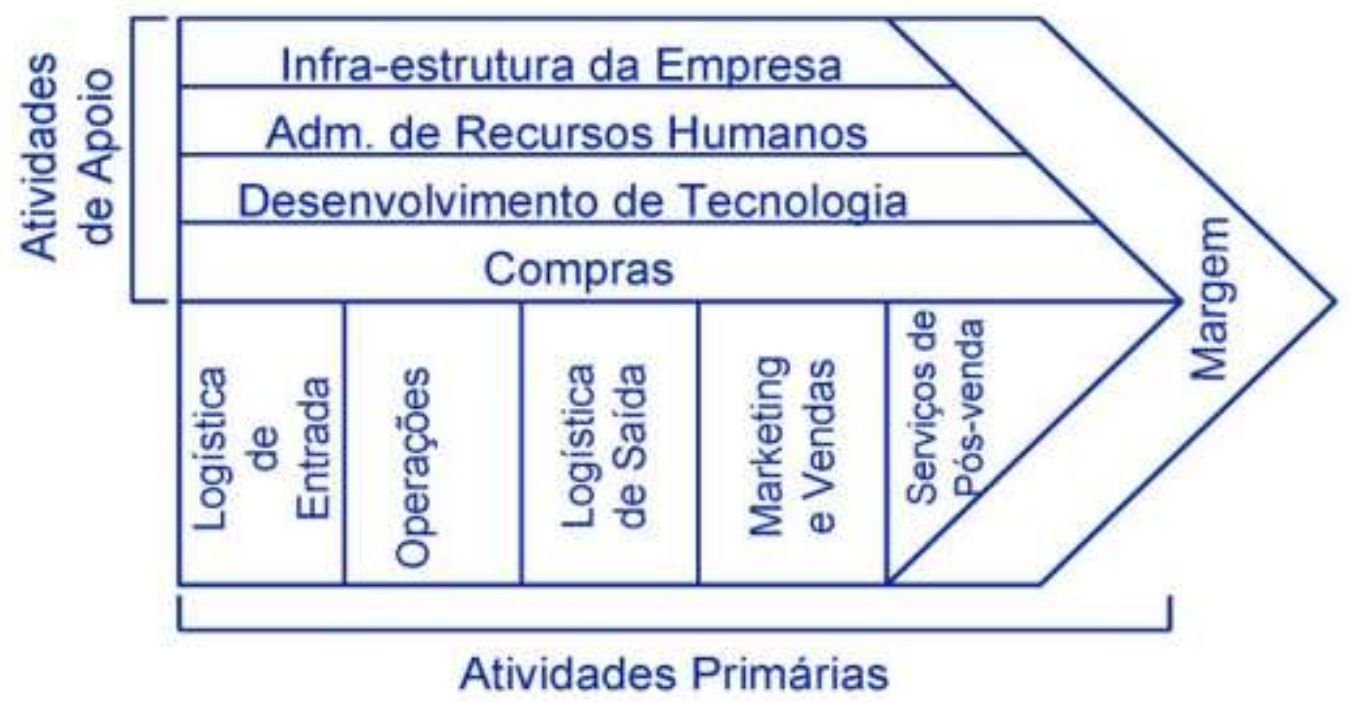

Fonte: Porter (1985).

Os componentes internos de uma cadeia de valor podem ser classificados em dois grupos: as atividades de apoio, que dão suporte aos processos produtivos, e as atividades primárias, que remetem ao próprio processo produtivo (Porter, 1989). As atividades de suporte incluem os processos secundários, ou seja, que não estão diretamente relacionados aos fins organizacionais, mas que são essenciais para o bom funcionamento das organizações e, sem eles, não haveria geração de valor; incluem a definição de regras, estabelecimento de metas, a gestão de recursos e o controle gerencial (Sengupta et al., 2006). As atividades principais, por sua vez, são aquelas que incluem o que está diretamente relacionado ao processo produtivo do 
produto ou à prestação do serviço para o cliente final (Nagariya, 2020). Desse modo, podemos afirmar que esses componentes internos e externos, quando alinhados aos objetivos estratégicos da organização, são considerados as unidades geradoras de valor (Armistead \& Clark, 1993).

O que se espera ao se realizar uma análise precisa de uma realidade organizacional em busca dos processos de geração de valor é, justamente, o mapeamento e detalhamento desses componentes, considerando seu alinhamento com os objetivos estratégicos da organização, as atividades realizadas por ela, e os resultados percebidos como "valor" (Koh \& Nam, 2005; Kaplinsky \& Moris, 2001; Jelassi \& Martínez-López, 2020). Ao final dessa investigação, isto é, com o entendimento adequado dos processos e elos de uma cadeia produtiva do ponto de vista da sua geração de valor, os resultados permitirão, posteriormente, identificar o "peso" de cada um desses elos que compõem a cadeia na geração de valor.

A importância de tal análise se encontra justificada por sua capacidade de garantir que a organização se dedique "máxima aristotélica", isto é, "fazer a coisa certa, da forma certa e na proporção correta". Desse modo, os esforços organizacionais, isto é, os processos e procedimentos necessários para a produção, passam ser concentrados nas atividades capazes de maximizar o valor de seus produtos ou serviços e, do mesmo modo, na melhoria e revisão das ineficiências desses processos. O resultado é criação de uma capacidade inimitável e sustentável pela organização, que permite sua diferenciação, em relação as demais, e garante sua continuidade (Bassi, Gasparotto \& Gonçalves, 2020).

Esse modelo de análise e identificação da cadeia de valor tem sido amplamente utilizado no setor de serviços (Heintzman \& Marson, 2005; Porter \& Teisberg, 2006; Reinartz, Wiegand \& Imschloss, 2019; Tseng et al., 2018). Do mesmo modo que o modelo proposto por Porter (1985), os estudos na área de serviço têm se concentrado em identificar atividades primárias, atividades de suporte, e nos participantes (stakeholders) da cadeia de valor de serviços (Vilela, et al., 2020). Nesse sentido, Simatupang \& Piboonrungroj (2017) concluem que a cadeia de valor no setor de serviços é similar às demais cadeias dos setores produtivos. Porém, a percepção do conceito de valor possui aspectos distintos, sendo este, o principal fator de diferenciação quando comparado a proposta do modelo aplicada ao setor de produtos.

\section{Procedimentos Metodológicos}

Adotando a premissa que o campo de estudo da administração, como ciência prática, pode contribuir para a melhoria dos processos escolares, este estudo estende a perspectiva de uso do modelo de Cadeia de valor de Porter (1985). Assim, o resultado da pesquisa visa conceber um Framework básico que caracteriza a geração de valor pela oferta dos serviços relativos à Educação pública. Para tanto, tornou-se necessário a investigação dos componentes e agentes desse processo. Dada a complexidade das organizações escolares, o modelo de cadeia de valor foi concebido considerando conceitos e princípios da realidade do sistema de ensino público brasileiro, após a constituição de 1988, especificamente na educação básica.

Para alcançar os fins pretendidos, os procedimentos adotados foram divididos em quatro etapas, conforme apresentado no fluxograma contido na Figura 2.

Figura 2. Fluxograma das etapas adotadas nos procedimentos metodológicos do estudo.

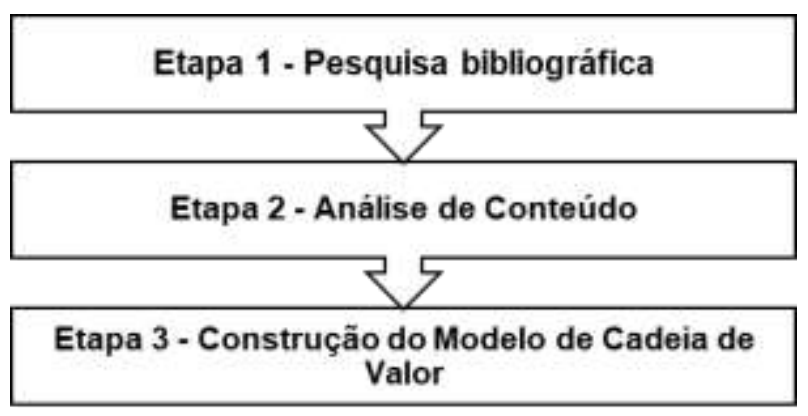

Fonte: Autores (2020). 
A primeira etapa do estudo consistiu numa pesquisa bibliográfica exploratória. Por pesquisa bibliográfica entende-se como o método de mapear a produção científica que versa sobre determinado tema (Yin, 2005). Nesse sentido, inicialmente, foram consultadas as bases acadêmica de dados Scielo e Spell, utilizando as palavras-chave: "educação básica"; "educação pública"; "escola" + "pública (o)"; "ensino" + "pública(o)". Foram selecionados apenas periódicos brasileiros com qualificação Qualis da CAPES. Na sequência, realizou-se a leitura dos resumos e selecionou-se apenas os trabalhos que, de fato, relacionavam-se ao tema da pesquisa. De modo complementar, recorreu-se às principais normas regulamentadoras do sistemas de ensino público (leis, decretos, portarias, regimentos internos). Por fim, organizou-se os textos publicados por tema central abordado.

Na segunda etapa, análise de conteúdo, realizou-se a leitura minuciosa dos trabalhos. Segundo Hair Jr. et al. (2005, p. 154), a análise de conteúdo é elaborada "por meio da análise sistemática e da observação, o pesquisador examina a frequência com as palavras e temas principais ocorrem e identificam o conteúdo e as características de informações presentes no texto". As interpretações inferenciais realizadas na análise de conteúdo tiveram como base os pressupostos estabelecidos com base na revisão da literatura. Os trabalhos foram analisados de forma crítica, a fim de se levantar as informações para identificar os principais componentes apontados como geradores de valor ao nível da escola e do sistema educacional público.

$\mathrm{Na}$ etapa três, construiu-se a proposta de cadeia de valor objeto deste estudo. As inferências obtidas pelo trabalho realizado nas etapas anteriores do estudo permitiram ao pesquisador construir um modelo nos moldes do framework proposto por Porter (1985). Para isso, considerou-se os apontamentos do que há de relevante sobre o desempenho da educação pública básica e que já fora investigado em estudos prévios do campo.

\section{Resultados e Discussões}

No que tange aos serviços de educação pública, podemos afirmar que o conceito mais sólido de valor direto observado na literatura consiste no próprio efeito-escola, entendido como "o quanto uma organização escolar, pelas suas políticas e práticas internas, acrescenta ao aprendizado do aluno" (Brooke \& Soares, 2008, p. 10). Por sua vez, o valor indireto pode ser melhor conceituado considerando os resultados sociais resultantes da oferta dos processos de ensino, como melhoria da qualidade de vida, empregabilidade, emancipação dos sujeitos (Oliveira \& Waldhelm, 2016).

Os participantes dessa cadeia de valor podem ser divididos em dois grupos, de acordo com o modo que eles estão envolvidos no processo de geração de valor ao longo da cadeia. O primeiro grupo consiste nas partes envolvidas diretamente com o serviço educacional: alunos, consumidores diretos dos serviços educacionais; agentes educacionais (professores, pedagogos e demais profissionais do campo do ensino), responsáveis pelas práticas pedagógicas; gestores escolares, responsáveis pelas práticas organizacionais. O segundo grupo, por sua vez, trata do conjunto de agentes envolvidos indiretamente com o serviço: agentes políticos, responsáveis pelas elaborações de leis e estabelecimento das políticas públicas; a sociedade, pois é afetada pelas externalidades positivas geradas pela prestação dos serviços educacionais pelo Estado.

A leitura dos textos e a interpretação com base na proposta teórica de Porter (1985) resultaram em um modelo capaz de explicar como esse valor é gerado no âmbito do ensino público básico. Conforme ilustrado na Figura 3, a cadeia de valor proposta é composta por duas atividades de suporte e duas atividades primárias, que serão detalhadas ao longo desse capítulo. As atividades de suporte (AS) definidas foram: (AS1) regulamentação e planejamento; (AS2) avaliação e acompanhamento. Já as atividades primárias (AP) de agregação de valor definidas foram: (AP1) Gestão escolar; (AP2) Atividades pedagógicas. 
Figura 3. Cadeia de Valor da Educação Básica Pública.

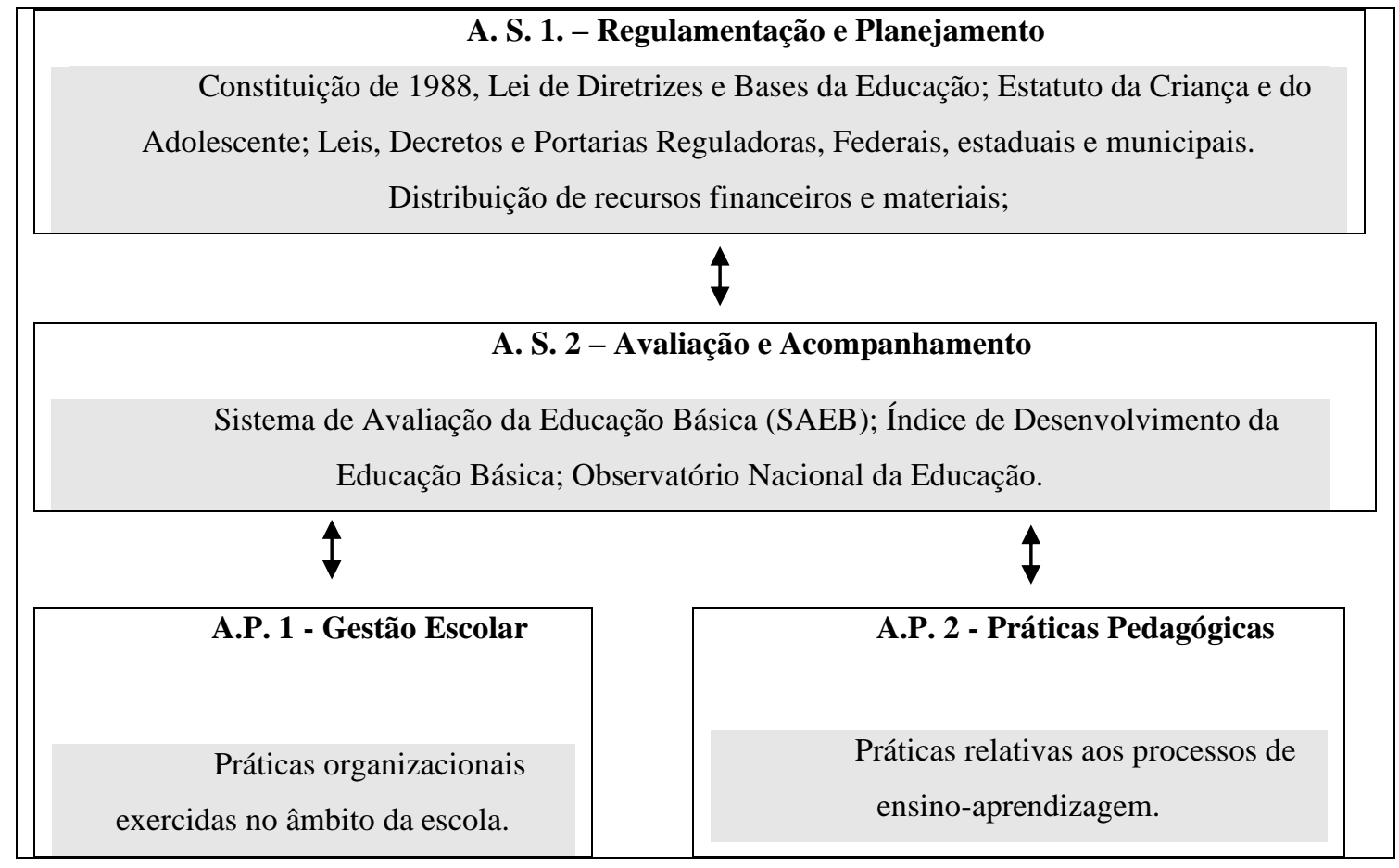

Fonte: Autores.

A primeira atividade de suporte (A.S.1) que compõe a cadeia de valor que propomos para a educação pública básica é regulamentação e planejamento do setor. Como aponta Maçães (2018), os aspectos relativos à regulamentação são de crucial importância na análise da cadeia de valor, pois são eles os determinantes das regras e orientações de como os processos devem ser feitos. No que tange aos serviços públicos, tal importância é, ainda, maior, pois, a regulamentação, além de definir as regras de atuação, é responsável por concretizar a abrangência da oferta material ou substantiva do serviço ofertado (Heintzman e Marson, 2005). Por isso, ela, por si só, pode ser percebida como uma atividade que compõe a cadeia de valor. Nesse sentido, elencamos os principais regramentos apontados pela literatura, alinhados com esses preceitos, e, deste modo, foram capazes de engajarem políticas públicas responsáveis por melhorar o nível da oferta de serviço e por gerar melhoria nos indicadores educacionais brasileiros: A Constituição Federal de 1988; o Estatuto da Criança e do Adolescente (ECA); a Lei de Diretrizes e Bases da Educação Nacional (LDB); os planos nacionais de educação.

A principal regulamentação apontada na literatura foi a Constituição Federal de 1988. Pois, foi a Carta de Direitos de 1988, que previu, pela primeira vez, a oferta pública e gratuita de ensino público para todas as pessoas. Para garantir a universalidade e eficácia na oferta, impôs-se aos entes federativos a obrigação de reservar recursos públicos para despesas com a manutenção e desenvolvimento do ensino (MDE), sendo 18\% para a União e 25\% para Estados e Municípios de todos os impostos arrecadas pelo ente federado. Isso permitiu uma ampliação dos recursos orçamentários destinados a oferta de serviços educacionais, que passou de 3,2\% do produto interno bruto (PIB) em 2000, para 4,1\% em 2017 (INEP, 2017).

Acompanhando a CF de 88, em 1990, promulgou-se o estatuto da criança e do adolescente (ECA), lei n 8.069/1990. Esse regramento infraconstitucional constituiu importante mecanismo impulsionador da melhoria da qualidade do ensino público, pois trouxe consigo uma série de normas de responsabilização as partes envolvidas no processo educacional (Müller \& Martinelli, 2005; Gimenez, Maciel \& Brabo, 2018). Para o Estado e o administrador público foi atribuído a responsabilidade de garantir que os alunos tivessem acesso à escola próxima a sua residência. Para o gestor da escola, impôs-se a obrigação de comunicar as autoridades legais diversos aspectos relacionados a dignidade do estudantes, que afetariam o seu processo de 
ensino aprendizagem, tais como: faltas em excesso, reprovações e evasão. Para os pais, foi determinada a obrigação de matricular seus filhos na escola.

Complementarmente, enquanto a CF de 88 e o ECA estabeleceram a obrigatoriedade da prestação dos serviços educacionais com qualidade, foi a nova Lei de Diretrizes e Bases da Educação Nacional (LDB) (Lei n 9.394 , de 20 de dezembro de 1996) e suas alterações (leis 11.114/2005 e 11.274/2006) que definiram "como" isso viria por acontecer. Desse modo, a LDB consolidou as diretrizes capazes de garantir a qualidade do ensino ofertado em sala de aula, definindo como recursos, pessoas e conteúdos pedagógicos deveriam ser organizados para a oferta dos serviços educacionais (Pereira \& Forte, 2008; Da Silva \& Nunes, 2020). Juntos, esses regramentos foram responsáveis por direcionar as atividades de geração de valor conhecido como de universalização da educação pública brasileira. Os seus resultados foram evidentes, em 2001, pois $95 \%$ das pessoas na faixa dos 7 aos 14 anos estavam matriculadas na escola e $79 \%$ desses alunos pertenciam à rede pública de ensino (INEP, 2017).

Ainda no âmbito dos processos de regulamentação dos serviços de educação pública, o planejamento ocupa espaço de destaque, por ter como propósito a definição dos objetivos e metas a serem buscados para que se alcance a melhoria da qualidade da educação pública nacional (Saviani, 2007). A CF de 88 estabeleceu que o planejamento dos serviços educacionais públicos deve ser feito via planos nacionais de educação (Garcia \& Hillesheim, 2017). Os objetivos desses planos consistem em estabelecer um conjunto de metas que garantam o cumprimento das diretrizes regulamentares estabelecidas, dentro de um determinado período. O plano nacional de educação vigente (2014-2024), estabelecido pela Lei Federal 13.005, determina 10 diretrizes e 20 metas para os serviços educacionais, que podem ser classificadas em quatro dimensões: disponibilidade, acessibilidade, aceitabilidade e adaptabilidade. Como aponta Ibañez (2019, p. 173):

Praticamente em todas as dimensões: disponibilidade, acessibilidade, aceitabilidade e adaptabilidade; encontramos metas e estratégias que buscam a igualdade, a equidade e a justeza, no cumprimento do direito à educação. Chamounos a atenção, por exemplo, a busca por abranger um público-alvo mais amplo possível. Pessoas com deficiência, crianças surdas, idosos, população do campo, filhos(as) de profissionais que se dedicam a atividades de caráter itinerante, adolescentes e jovens em situação de rua, pessoas privadas de liberdade, entre outras, foram contempladas pelo Plano. Dessa forma, observamos que o Plano em si, ao menos enquanto designíos dos legisladores, possui uma série de virtudes que devem ser valorizadas, quer seja pela abrangência e profundidade das questões abordadas, ou por propor medidas muito ousadas e progressistas para os problemas atuais.

Assim, conforme os apontamentos feitos para A.S1, considerou-se que em um processo de regulamentação capaz de gerar valor, as partes interessadas devem garantir princípios, normas e diretrizes que orientem a prestação de serviços educacionais alinhando esta prestação com as características de um bem público: gratuito, universal e com qualidade. Chagas e Cardoso (2018, p. 61) apontam que a "introdução desses conceitos pode levar à eficiência, responsabilidade e avaliação de desempenho". Do mesmo modo, a busca pela prestação de serviços com qualidade por meio do estabelecimento de planos educacionais está diretamente relacionada à melhoria da percepção subjetiva de valor e da confiança da sociedade no Estado, pois se trata de um forte indicativo de comprometimento em prover serviços público com qualidade (Heintzman \& Marson, 2005).

A segunda atividade de suporte da cadeia proposta é A.S. 2 - Avaliação e Acompanhamento. Nela se incluem os processos necessários para avaliar o cumprimento dos objetivos e metas que foram definidos nos planos de educação, assim como, os mecanismos de acompanhamento para garantir que o que foi planejado está sendo realizado. Avaliar e acompanhar são processos organizacionais distintos, porém indissociáveis na cadeia de valor proposta. Pois, enquanto avaliar implica desenvolver um conjunto de indicadores de desempenho, acompanhar significar fazer o uso desses indicadores para verificar se a execução das atividades está dentro das especificações e prazos necessários para o alcance dos objetivos e metas estabelecidos (Moraes, Menezes \& Dias, 2019). 
Consideremos que na prestação de serviços educacionais, o processo de avaliar e acompanhar gera valor por ser, justamente, o elo necessário para se averiguar o alinhamento entre as atividades primárias da cadeia (AP) com a atividade de regulamentação e planejamento (AS1). A verificação desse alinhamento para a prestação de serviços deve ser feita a partir do desempenho contextualizado, ou seja, o ponto de partida e chegada em termos de melhores níveis de aprendizagem, a partir do contexto socioeconômico em que a escola está inserida. Nesse sentido, Cappelletti (2015, p. 102) aponta que:

Se a avaliação educacional for concebida pelo gestor como acaba de ser discutida, numa perspectiva globalizante com forte apelo social, por certo terá à sua disposição informações valiosas sobre o desenvolvimento do trabalho escolar. Terá pistas, alternativas de ação para promover o desenvolvimento curricular em sua escola, assumindo sua função principal de gerir e criar cultura.

A avaliação da educação pública brasileira vem sendo feita por meio do Sistema de Avaliação da Educação Básica (SAEB). Criado em 1990, o SAEB é responsável por realizar as avaliações externas de larga escala das escolas brasileiras, gerando, assim, um conjunto de indicadores fundamentais para o diagnóstico das condições da oferta dos serviços educacionais. De acordo com o Ministério da Educação (Fernandes, 2017, p. 1), "a avaliação é um procedimento necessário para definir prioridades e garantir a qualidade do ensino, por isso a União elaborou um sistema de avaliação capaz de diagnosticar e indicar necessidades de controle e correções de rumos na política educacional coordenada pelo próprio MEC, em colaboração com os Estados e Municípios".

Compõe o SAEB: a ANRESC - Avaliação Nacional do Rendimento Escolar, também conhecida como prova Brasil; e a ANEB - Avaliação Nacional da Educação Básica. Cabe dizer que "estas avaliações produzem informações que subsidiam a formulação, reformulação e o monitoramento das políticas públicas nas esferas municipal, estadual e federal” (INEP, 2014, p. 1). Elas também são acompanhadas por um conjunto de informações sobre a escola que permitem contextualizar esses resultados, sendo o mais importante o indicador de nível socioeconômico (INSE), "uma medida cujo objetivo é situar o conjunto dos alunos atendidos por cada escola em um estrato, definido pela posse de bens domésticos, renda e contratação de serviços pela família dos alunos e pelo nível de escolaridade de seus pais" (INEP, 2014, p. 1).

Em 2007, utilizando dos resultados do SAEB, a avaliação da educação básica ganhou seu principal indicador, o Índice de Desenvolvimento da Educação Básica (IDEB). A importância desse indicador se dá por que em seu cálculo se considera "necessário avaliar não apenas os conhecimentos e habilidades adquiridas pelos estudantes ao final da etapa específica, mas também o tempo necessário para concluí-la" (Fernandes, 2007, p 9). Seu cálculo é feito a partir dos resultados da prova Brasil em conjunto o indicador de fluxo escolar, isto é, o valor do IDEB de uma escola ou rede de ensino é o resultado da equação em que se divide a média dos resultados obtidos na Prova Brasil e o tempo médio de conclusão de cada série. Como informa o decreto $\mathrm{n}^{\circ} 6.094$ de 24 de abril de 2007 :

Art. $3^{\circ}$ - A qualidade da educação básica será aferida, objetivamente, com base no Ideb, calculado e divulgado periodicamente pelo Inep, a partir dos dados sobre rendimento escolar, combinados com o desempenho dos alunos, constantes do censo escolar e do Sistema de Avaliação da Educação Básica - Saeb, composto pela Avaliação Nacional da Educação Básica - Aneb e a Avaliação Nacional do Rendimento Escolar (Prova Brasil).

Outro importante processo desse elo da cadeia é o monitoramento realizado pelo Observatório da Educação, órgão que responde pelo monitoramento da qualidade de ensino nacional. Criado em 2006, pela União, o Observatório tem como missão "monitorar o Plano Nacional de Educação, dando transparência aos dados da Educação brasileira e contribuindo para que o PNE siga como uma agenda norteadora das políticas educacionais" (ONE, 2021, p.1). Além disso, o órgão incentiva por meio de financiamentos estudos e pesquisas que visem identificar problemas e propor soluções para garantir melhores níveis de qualidade na educação pública brasileira. 
Em continuidade ao detalhamento da cadeia proposta, a primeira atividade principal que propomos para compor a cadeia de valor é a AP1 - Gestão Escolar. Por gestão escolar entende-se não apenas as atividades exercidas pelo diretor da escola, mas pelo conjunto de todas as ações humanas com fins organizacionais que acontecem na escola, ou seja, o conjunto de práticas organizacionais (Misoczky \& Moraes, 2017). Schatzki (2005, p. 471) define os componentes que compõem uma prática organizacional como "o conjunto de ações que compõe uma prática é organizado por três fenômenos: o entendimento de como fazer as coisas, as regras e a estrutura teleoafetiva".

Como aponta Moraes et at. (2020. p. 21), um conjunto de boas práticas organizacionais é "fundamental para a obtenção de bons resultados na aprendizagem e para a melhoria contínua do desempenho escolar". Por isso, a gestão escolar, aí entendida como prática organizacional, é um dos elos fundamentais dessa cadeia de geração de valor. No Brasil, estudos recentes têm apontado que escolas em mesmas condições de recursos e níveis socioeconômicos conseguem obter resultados, em termos de desempenho escolar, significativamente diferentes, a depender das práticas organizacionais da escola (Moraes et al. 2020).

Entre as práticas apontadas pela literatura como capazes de gerar valor ao sistema de ensino público, três se destacam: a relação com a comunidade, garantindo que a escola seja percebida pela comunidade como como um agente transformador da realidade em que se encontra inserida (Delgado et al., 2021); O trabalho em equipe, responsável por criar um ambiente de afetos positivos, fundamental ao processo de ensino aprendizagem (Vieira \& Bussolotti, 2018); o desenvolvimento de altas expectativas em relação aos objetivos de aprendizagem nos alunos e professores, motivando a busca por processos de ensino cada vez mais eficazes (Passone, 2019).

Ainda, cabe ressaltar que o desenvolvimento dessas práticas não ocorre de forma autônoma. Como aponta Moraes, Mariano e Dias (2021, p.2) “uma das fragilidades do sistema público de ensino brasileiro, especialmente na educação básica, é a distância entre as competências exigidas para o cargo de diretor da escola e a capacidade real dos diretores para desenvolver as funções inerentes ao cargo". Ou seja, para que a gestão escolar possa se empoderar de tais práticas geradoras de valor, é necessária uma ação governamental através de regulamentações, planos e políticas de capacitação orientadas para esses fins.

Por fim, a segunda atividade primária é a A.P. 2 - Práticas Pedagógicas, que estão relacionadas ao processo ensinoaprendizagem, ou seja, "o campo do conhecimento que se ocupa do estudo sistemático da educação" (Libâneo, 2001, p. 6). A prática pedagógica é a atividade core da escola, isto é, a atividade com maior capacidade de geração de valor da cadeia analisada (Moares, Mariano \& Dias, 2021). Para que essa atividade seja desempenhada com sucesso, faz-se necessário o adequado funcionamento das demais atividades da cadeia.

\section{Considerações Finais}

Nesse estudo, nos propusemos a apresentar um possível modelo de cadeia de valor para a educação pública básica brasileira, sem porém, esgotar outras possibilidades ou modelos existentes. A contribuição desse estudo está em defender a pertinência da ideia de que a investigação sobre como se gera valor no fornecimento dos serviços de educação pública básica pode vir a contribuir para a melhoria da qualidade do próprio ensino público brasileiro.

$\mathrm{Na}$ tentativa de entender um pouco mais como o valor é gerado para as partes interessadas nesse serviço, nos valemos do modelo teórico de Porter (1985). Por meio de um estudo aprofundado do que os pesquisadores desse campo apontam como importante para a melhoria dos serviços educacionais, foi possível caracterizar, de forma genérica, as atividades percebidas como geradoras de valor. Assim, a cadeia proposta é formada por duas atividades secundárias (A.S) e duas atividades primárias (A.P): (A.S.1) Regulamentação e Planejamento; (A.S.2) Avaliação e Acompanhamento; (A.P.1) Gestão Escolar; (A.P. 2) Práticas Pedagógicas. 
Os dois componentes de apoio e os dois componentes primários que compõem a cadeia representam, de forma genérica e abrangente, todo o esforço que o Estado brasileiro e a sociedade brasileira têm feito para melhoria da qualidade do ensino ofertado no Brasil desde a Constituição de 1988. Nesse sentido, o que se observa é que a geração de valor em serviços educacionais públicos depende, predominantemente, de um adequado processo de integração entre todas essas atividades.

Desse modo, consideramos que o modelo proposto, apesar de genérico, fornece uma visão macro sobre as relações entre as atividades da cadeia e a geração de valor. Desse modo, uma investigação holística sobre todo o processo traz como contribuição a facilitação de estudos futuros, que podem se dedicar a apenas um dos elos da cadeia, à integração entre os elos, à melhoria sistémica dos processos realizados ou até mesmo a entender o impacto dos processos sobre cada uma das partes que participam, direta ou indiretamente, dos benefícios gerados pela cadeia de valor proposta. Por fim, para estudos futuros, recomendamos a continuidade do processo de investigação de outros fatores que possam vir a agregar valor a cadeia proposta, assim como, o entendimento detalhado de como esses fatores se relacionam.

\section{Referências}

Araújo, G. C., Cassini, S. A. (2017). Contribuições para a defesa da escola pública como garantia do direito à educação: aportes conceituais para a compreensão da educação como serviço, direito e bem público. Revista Brasileira de Estudos Pedagógicos, 98(250), 561-579.

Armistead, C. G., Clark, G. (1993). Resource activity mapping: the value chain in service operations strategy. Service Industries Journal, 13(4), 221-239.

Bassi, W. D. G., Gasparotto, A. M. S., Gonçalves, G. I. (2020). Desenvolvimento sustentável como vantagem competitiva na geração de valor para as organizações empresariais. Revista Interface Tecnológica, 17(1), 279-291.

Brooke, N., Soares, J. F. (2008). Pesquisa em eficácia escolar: origem e trajetórias. UFMG.

Cappelletti, I. F. (2015). Os conflitos na relação avaliação e qualidade da educação. Educar em Revista, 1(SPE1), 93-107.

Chagas, G. L. M., Cardoso, A. L. J. (2018). A adoção do Planejamento Estratégico Municipal e a Geração de Valor compartilhado. Desafio Online, 6(1), 4369.

Da Silva, J. M., Nunes, V. G. C. (2020) Formação continuada docente: uma análise a partir da Lei de Diretrizes e Bases da Educação Nacional (LDB/1996) e das Diretrizes Curriculares Nacionais para a Formação Inicial e Continuada de Professores da Educação Básica (Resolução CNE-CP 2/2015). Research, Society and Development, 9(8), 1-22.

De Mira, A. P. V. J., De Carvalho, V. C. A. (2020). Gestão escolar humanizadora: possibilidades na promoção da educação em direitos humanos. Revista Educação e Emancipação, 13(1), 163-182.

Delgado, J. P., Carvalho, J. M., Romão, P., Martins, P. (2021). Que fatores contribuem para o sucesso da gestão escolar? A perspectiva dos diretores. Revista Portuguesa de Educação, 34(1), 73-94.

Fernandes, R. (2007) Índice de desenvolvimento da educação básica (IDEB). MEC--Ministério da Educação, INEP-Instituto Nacional de Estudos e Pesquisas Educacionais Anísio Teixeira.

Garcia, A. V., Hillesheim, J. (2017). Pobreza e desigualdades educacionais: uma análise com base nos Planos Nacionais de Educação e nos Planos Plurianuais Federais. Educar em Revista, 1(SPE. 2), 131-147.

Gimenez, M. Z., Maciel, T. S., Brabo, T. S. A. M. (2018). Educação e cidadania: uma experiência pedagógica sobre o Estatuto da Criança e do Adolescente em escola de Ensino Fundamental. Horizontes, 36(2), 142-153.

Hair Jr., J. F. (2005) Fundamentos de métodos de pesquisa em administração. Bookman.

Haddad, S., Siqueira, F. (2015). Analfabetismo entre jovens e adultos no Brasil. Revista Brasileira de Alfabetização, 1(2), 88-110.

Heintzman, R., Marson, B. (2005). People, service and trust: is there a public sector service value chain? International Review of Administrative Sciences, 71(4), 549-575

INEP. (2014). Nota Técnica: Indicador de nível socioeconômico (inse) das escolas. Instituto Nacional de Estudos e Pesquisas Educacionais Anísio Teixeira (INEP).http://download.inep.gov.br/informacoes_estatisticas/indicadores_educacionais/2011_2013/nivel_socioeconomico/nota_tecnica_indicador_nivel_socio economico.pdf.

INEP. Saeb. (2017). Instituto Nacional de Estudos e Pesquisas Educacionais Anísio Teixeira (INEP). http://portal.inep.gov.br/web/guest/educacaobasica/saeb.

Jardim, A. C., Varandas, C. D. S. P., Peres, V. N., de Barros, A. S., J. A. C., Da Silva, E. L. D. O. (2015). Cadeia de valores: estudo de caso múltiplo em buffets infantis na cidade de Santos (SP). Revista Eletrônica de Estratégia \& Negócios, 8(1), 85-119.

Jelassi, T., Martínez-López, F. J. (2020). Internal Analysis: e-Business Competencies as Sources of Strengths and Weaknesses. In Strategies for eBusiness (97-124). Springer, Cham. 
Kaplinsky, R., Morris, M. (2001). A Handbook for Value Chain Research, IDRC. International.

Koh, C. E., Nam, K.. (2005). Business use of the internet: a longitudinal study from a value chain perspective. Industrial Management e Data Systems, 105(1), $82-95$.

Libâneo, J. C.. Pedagogia e pedagogos: inquietações e buscas. (2001). Educar em Revista, 1(17), 153-176.

Maçães, M. A. R.. (2018). Vantagem Competitiva e Criação de Valor. Leya.

Misoczky, M. C. A., Moraes, J.. (2017). Organisation and liberating praxis in social movement schools. EDUFF.

Moraes, J., Menezes, D. T., Dias, B. F. B. (2019). Uma análise contextualizada dos resultados das escolas públicas brasileiras. Revista Meta: Avaliação, $11(31), 67-96$.

Moraes, J., Manoel, M. V., Dias, B. F. B., Mariano, S. R. H. (2020). Organizational practices in high performance public schools in Brazil. REICE: Revista Iberoamericana sobre Calidad, Eficacia y Cambio en Educación, 18(1), 5-25.

Moraes, J., Mariano, S. R. H., \& Dias, B. F. B. (2021). A eficácia da formação em gestão para gestores de escolas públicas. Revista de Gestão e Avaliação Educacional, 10(19), 1-21.

Müller, V. R., Martineli, T. A. P. (2005). O estatuto da criança e do adolescente: um instrumento legal do professor de Educação Física. Revista Brasileira de Ciências do Esporte, 26(3), 9-24.

Nagariya, R., Kumar, D., Kumar, I. (2020). Service supply chain: from bibliometric analysis to content analysis, current research trends and future research directions. Benchmarking: An International Journal, 28(1), 333-369.

Oliveira, A. C. P. D., \& Waldhelm, A. P. S. (2016). Liderança do diretor, clima escolar e desempenho dos alunos: qual a relação? Ensaio: Avaliação $e$ Políticas Públicas em Educação, 24(93), 824-844.

Parasuraman, A., Zeithaml, V. A., \& Berry, L. L. (1985). A conceptual model of service quality and its implications for future research. Journal of marketing, 49(4), 41-50.

Passone, E. F. K. (2019). Gestão Escolar e Democracia: o que nos ensinam os estudos de Eficácia Escolar. Laplage em revista, 5(2), $142-156$.

Pereira, M. S., Forte, S. H. A. C. (2008). Visão baseada em recursos nas instituições de ensino superior de Fortaleza: uma análise ex-ante e ex-post à LDB/96. Revista de Administração Contemporânea, 12(1), 107-129.

Porter, M. E. (1985) Competitive advantage: creating and sustaining superior performance. The Free Press.

Porter, M. E. (1999). Vantagem competitiva: criando e sustentando um desempenho superior. Campus.

Porter, M. E., Teisberg, E. O.. (2006) Redefining health care: creating value-based competition on results. Massachusetts: Harvard business press.

Saviani, D.. (2007) O Plano de Desenvolvimento da Educação: análise do projeto do MEC. Educação e Sociedade, 28(100), 1231-1255.

ONE. (2021). Objetivos. Observatório Nascional da Educação (ONE). https://www.observatoriodopne.org.br.

Schatzki, T. (2005). The sites of organizations. Organization Studies, 26(03), 465-484.

Sengupta, K., Heiser, D. R., Cook, L. S. (2006). Manufacturing and service supply chain performance: a comparative analysis. Journal of supply chain management, 42(4), 4-15.

Simatupang, T. M., Piboonrungroj, P., Williams, S. J. (2017). The emergence of value chain thinking. International Journal of value chain management, 8(1), 40-57.

Sobrinho, J. D.. (2013) Educação superior: bem público, equidade e democratização. Avaliação: Revista da Avaliação da Educação Superior, 18(1), 107-126.

Reinartz, W., Wiegand, N., \& Imschloss, M. (2019). The impact of digital transformation on the retailing value chain. International Journal of Research in Marketing, 36(3), 350-366.

Tseng, M. L., Wu, K. J., Chiu, A. S., Lim, M. K., \& Tan, K. (2018). Reprint of: Service innovation in sustainable product service systems: Improving performance under linguistic preferences. International Journal of Production Economics, 217(19), 159-170.

Vieira, A. E. R., Bussolotti, J. M.. (2018) Gestão escolar. Interação-Revista de Ensino, Pesquisa e Extensão, 20(1), 45-70.

Vilela, F. F., Segismondi, L. C., Piedade, L. D. D. C., Montevechi, J. A. B., Piedade, D. D. D. C. (2020). Aplicação do mapeamento da cadeia de valor: um estudo de caso em uma lavanderia hospitalar. Brazilian Journal of Development, 6(1), 4440-4449.

Zeithaml, V. A., Bitner, M. J., \& Gremler, D. D. (2014). Marketing de serviços: a empresa com foco no cliente. AMGH Editora.

Yin, R. K. (2015). Estudo de Caso: Planejamento e métodos. Bookman Editora. 